\title{
Produção de fitomassa por plantas de cobertura e mineralização de seus resíduos em plantio direto
}

\author{
Jose Luiz Rodrigues Torres ${ }^{(1)}$, Marcos Gervasio Pereira(2) e Adelar José Fabian(1)
}

\begin{abstract}
(1)Centro Federal de Educação Tecnológica de Uberaba, Av. Edílson Lamartine Mendes, № 300, CEP 38045-000 Uberaba, MG. E-mail: jlrtorres@terra.com.br, ajfabian@cefetuberaba.edu.br (2)Universidade Federal Rural do Rio de Janeiro, Departamento de Solos, BR 465, Km 7, CEP 23890-000 Seropédica, RJ. E-mail: gervasio@ufrrj.br
\end{abstract}

Resumo - O objetivo deste trabalho foi avaliar a produção de fitomassa seca, a taxa de decomposição das palhadas e as quantidades de macronutrientes (N, P, Ca, Mg e S) liberadas dos resíduos vegetais de sete plantas de cobertura de solo, em condições de Cerrado, por dois anos. As plantas de cobertura avaliadas foram: milheto (Pennisetum americanum sin. typhoides), braquiária (Brachiaria brizantha cv. Marandu), sorgo forrageiro [Sorghum bicolor (L.) Moench], guandu [Cajanus cajan (L.) Millsp.], crotalária juncea (Crotalaria juncea L.), aveia-preta (Avena strigosa Schreb) e a vegetação espontânea de uma parcela em pousio. Utilizou-se o delineamento em blocos ao acaso, com quatro repetições, implantado em um Latossolo Vermelho, textura média. Avaliou-se a produção de fitomassa seca 110 dias após a semeadura. A taxa de decomposição foi quantificada por meio de sacolas de náilon contendo os resíduos culturais, coletadas em intervalos regulares. Observou-se que milheto e crotalária são as coberturas gramínea e leguminosa com maior produção de fitomassa seca e acúmulo de $\mathrm{N}$, nos dois períodos avaliados. A maior taxa de decomposição das plantas de cobertura e de liberação de nutrientes ocorre aos 42 dias após a dessecação. Os maiores tempos de meia-vida foram observados no período de menor precipitação pluvial.

Termos para indexação: Avena strigosa, Cajanus cajan, Crotalaria juncea, Pennisetum americanum, meia-vida, taxa de decomposição.

\section{Cover crops biomass production and its residues mineralization in a Brazilian no-till Oxisol}

\begin{abstract}
The objective of this work was to evaluate dry biomass production, decomposition rate and macronutrients release (N, P, Ca, Mg and S) of cover crops cultural residues, in a no-till savanna soil. The cover crops tested were: pearl millet (Pennisetum americanum sin. typhoides), brachiaria grass (Brachiaria brizantha cv. Marandu), sorghum [Sorghum bicolor (L.) Moench], pigeon pea [Cajanus cajan (L.) Millsp.], sunn hemp (Crotalaria juncea L.) and black oat (Avena strigosa Schreb), compared to a fallow plot (control). The experiment was carried out in an Oxisol, medium texture. A randomized block design, in a split-plot array in time, with four replications, was used. Dry biomass production was evaluated 110 days after sowing. Decomposition rate was evaluated by litter bags containing cultural residues. Millet and sunn hemp are the cover crops (grass and legume) with the highest dry biomass production and $\mathrm{N}$ accumulation, in the two evaluation periods. The highest decomposition rate and nutrient release occurred at 42 days after desiccation. The highest values of half life were observed in dry period.
\end{abstract}

Index terms: Avena strigosa, Cajanus cajan, Crotalaria juncea, Pennisetum americanum, half life, decomposition rotes.

\section{Introdução}

O sistema de semeadura direta na palha tornou-se importante instrumento para a manutenção e recuperação da capacidade produtiva de solos manejados convencionalmente e de áreas degradadas. Na safra 2005/2006, 25,5 milhões de hectares foram cultivados sob este sistema (Federação Brasileira de Plantio Direto na Palha, 2007), que, no Cerrado, apresentou uma extensão de mais de 20 milhões de hectares (Caires et al., 2006). A eficácia desse sistema está relacionada, entre outros fatores, com a quantidade e a qualidade de resíduos produzidos por plantas de cobertura (Torres, 2003).

Vários estudos têm demonstrado os efeitos benéficos das plantas de cobertura nas propriedades do solo e no 
rendimento das culturas, decorrentes da produção de fitomassa, acúmulo e posterior liberação de nutrientes, pela decomposição da palhada (Bertol et al., 1998; Aita et al., 2001; Aita \& Giacomini, 2003; Torres et al., 2005; Espíndola et al., 2006; Boer et al., 2007; Gama-Rodrigues et al., 2007).

Ao estudar a velocidade de decomposição e mineralização de nutrientes em sorgo e milheto, no Cerrado, Moraes (2001) observou que a taxa média de decomposição da palhada é maior nos primeiros 42 dias após o manejo (DAM) e que a mineralização dos nutrientes é mais acentuada nos primeiros 63 DAM. Bertol et al. (1998) verificaram que, após 180 dias, a aveia-preta apresentou diminuição de $80 \%$ da fitomassa seca remanescente, quando incorporada ao solo. Silva et al. (1997) avaliaram a taxa de decomposição de crotalária, guandu, mucuna-preta e braquiária aos $60 \mathrm{DAM}$ em solo sob cerrado nativo, e obtiveram taxas de decomposição de 61,3, 61,9, 65,6 e $78,9 \%$, respectivamente. $\mathrm{Na}$ avaliação da decomposição de resíduos culturais de aveia-preta, ervilhaca e nabo forrageiro, Aita \& Giacomini (2003) observaram que, ao final de 30 DAM, 81, 57 e $75 \%$ da fitomassa seca, respectivamente, permaneciam na superfície do solo, quando cultivados de forma solteira. Salmi et al. (2006), trabalhando com guandu, observaram que $75 \%$ da fitomassa seca permaneciam sobre o solo 30 dias após a deposição.

Embora trabalhos de pesquisa, tais como os de Silva et al. (1997), Moraes (2001), Torres et al. (2005), Kliemann et al. (2006) e Boer et al. (2007), tenham sido conduzidos com o objetivo de avaliar a produção de fitomassa e a liberação de nutrientes em áreas de cerrado, ainda existe carência de informações sobre o processo de mineralização de nutrientes durante um período mais prolongado de tempo, no sistema de plantio direto.

O objetivo deste trabalho foi avaliar a produção de fitomassa seca, a taxa de decomposição e a liberação dos nutrientes dos resíduos vegetais de plantas de cobertura de solo, por dois anos consecutivos no Cerrado.

\section{Material e Métodos}

O estudo foi desenvolvido na área experimental do Centro Federal de Educação Tecnológica de Uberaba (Cefet), no Município de Uberaba, MG, localizado a $19^{\circ} 39^{\prime} 19^{\prime \prime} \mathrm{S}$ e $47^{\circ} 57^{\prime} 27^{\prime \prime} \mathrm{W}$, a aproximadamente $795 \mathrm{~m}$ de altitude, no período de agosto de 2000 a julho de 2001, numa área que estava há mais de um ano em pousio, e apresentava histórico de mais de 20 anos em plantio convencional com milho e soja rotacionados.

O solo da área experimental foi classificado como Latossolo Vermelho (Embrapa, 1999), com as seguintes características na camada arável $(0-20 \mathrm{~cm}): 180 \mathrm{~g} \mathrm{~kg}^{-1}$ de argila, $730 \mathrm{~g} \mathrm{~kg}^{-1}$ de areia e $90 \mathrm{~g} \mathrm{~kg}^{-1}$ de silte, pH $\mathrm{H}_{2} \mathrm{O}(1: 2,5) 6,3 ; 17 \mathrm{mg} \mathrm{dm}^{-3}$ de P (Mehlich 1); $96 \mathrm{mg} \mathrm{dm}^{-3}$ de K$; 1,9 \mathrm{cmol}_{\mathrm{c}} \mathrm{dm}^{-3} \mathrm{de} \mathrm{Ca}^{2+} ; 0,6 \mathrm{cmol}_{\mathrm{c}} \mathrm{dm}^{-3}$ de $\mathrm{Mg}^{2+} ; 2,0 \mathrm{cmol}_{\mathrm{c}} \mathrm{dm}^{-3}$ de $\mathrm{H}+\mathrm{Al}$ e $16 \mathrm{~g} \mathrm{dm}^{-3}$ de matéria orgânica.

As variações climáticas ocorridas na temperatura e precipitação no período de experimentação são apresentadas na Figura 1. As médias anuais de temperatura máxima e mínima $\left({ }^{\circ} \mathrm{C}\right)$, precipitação média anual $\left(\mathrm{mm}^{2} \mathrm{ano}^{-1}\right)$, insolação média anual (horas) e umidade relativa média anual do ar (\%), em um período de dez anos, foram de 29,0, 16,9, $1.639,6,360,4$ e 64,9, respectivamente (Abdala, 2005). O clima da região é classificado como Aw, tropical quente, segundo a classificação de Köppen, apresentando inverno frio e seco.

O delineamento experimental adotado foi o de blocos ao acaso, com parcelas subdivididas no tempo, e quatro repetições. As parcelas foram constituídas de sete tipos de coberturas vegetais, cada uma com área de $40 \mathrm{~m}^{2}$ (4x10 m). Após a dessecação, foram cultivados milho e soja sobre as plantas de cobertura. Antes da implantação das plantas de cobertura, realizou-se o controle das plantas invasoras na área do experimento.

Inicialmente, foi realizado o preparo convencional da área utilizando grade aradora com discos de 28 " e niveladora com discos de 20". Logo em seguida ao preparo, fez-se a sulcagem com espaçamento de $0,45 \mathrm{~m}$ entre as linhas de plantio com uma semeadora para plantio direto sem as rodas para cobertura de sementes. A semeadura e a cobertura das sementes foram efetuadas manualmente.

O estudo com as coberturas vegetais foi desenvolvido em duas etapas: a primeira fase do experimento ocorreu de agosto a novembro de 2000 e antecedeu o cultivo das culturas anuais. A segunda fase ocorreu no período de safrinha, de abril a julho de 2001, após o cultivo das culturas anuais.

A implantação do experimento consistiu na semeadura e cultivo das plantas de cobertura: milheto 
(Pennisetum americanum sin. tiphoydes), braquiária (Brachiaria brizantha cv. Marandu), sorgo forrageiro [Sorghum bicolor (L.) Moench], guandu [Cajanus cajan (L.) Millsp.], crotalária juncea (Crotalarea juncea L.), aveia-preta (Avena strigosa Schreb), pousio (vegetação espontânea). Na área de pousio, foi realizada a identificação da vegetação espontânea, e constatou-se a presença de espécies de diversas famílias, com predomínio de gramíneas, principalmente Cenchrus echinatus L., Digitaria insularis, Brachiaria plantaginea, Rhynchelytrum repens, Brachiaria decumbens, Eleusine indica, Panicum maximum. Não foi utilizado qualquer tipo de adubação ou irrigação para o cultivo das plantas de cobertura.

A avaliação da fitomassa seca (FS) foi realizada aos 110 dias após a semeadura (DAS) das plantas de cobertura, no estádio de pleno florescimento da maioria das coberturas, nas duas épocas de avaliação. Nesta avaliação, portanto, não se levou em consideração a rebrota das plantas de cobertura. A amostragem das coberturas foi realizada em dois pontos ao acaso em cada parcela, numa área de $1 \mathrm{~m}^{2}$, demarcada por um quadro metálico, lançado aleatoriamente na parcela. Esse material vegetal foi levado ao laboratório, colocado em estufa de circulação de ar forçada a $65^{\circ} \mathrm{C}$ por 72 horas, e posteriormente pesado. Os resultados foram expressos em quilogramas por hectare.

Após a amostragem, as coberturas foram dessecadas, aplicando-se $1.440 \mathrm{~g} \mathrm{ha}^{-1}$ de glifosato + $600 \mathrm{~g} \mathrm{ha}^{-1}$ de Paraquat e, após 15 dias, foram semeados milho ou soja. Depois da colheita das culturas anuais, em março e abril de 2001, foram semeadas novamente as coberturas vegetais, nos mesmos locais, sendo estas também dessecadas aos 110 DAS.

O híbrido duplo de milho AG 1051, da Agroceres, foi plantado com seis sementes por metro e $90 \mathrm{~cm}$ de espaçamento entre linhas, e a soja MG/BR-46 Conquista com 15 sementes por metro e espaçamento de $45 \mathrm{~cm}$ entre linhas. Na adubação de plantio de milho, utilizaram-se $32 \mathrm{~kg} \mathrm{ha}^{-1}$ de $\mathrm{N}, 80 \mathrm{~kg} \mathrm{ha}^{-1} \mathrm{de}$ $\mathrm{P}_{2} \mathrm{O}_{5}, 80 \mathrm{~kg} \mathrm{ha}^{-1}$ de $\mathrm{K}_{2} \mathrm{O}$ e $1,2 \mathrm{~kg} \mathrm{ha}^{-1}$ de $\mathrm{Zn}$. Em cobertura, aplicaram-se $90 \mathrm{~kg} \mathrm{ha}^{-1} \mathrm{de} \mathrm{N}$, na forma de uréia, aos dez dias após emergência (DAE) e mais $20 \mathrm{~kg} \mathrm{ha}^{-1}$ de $\mathrm{N}$ na forma de sulfato de amônia
25 DAE, nos dois anos agrícolas avaliados. Para soja, utilizou-se $8 \mathrm{~kg} \mathrm{ha}^{-1}$ de $\mathrm{N}, 80 \mathrm{~kg} \mathrm{ha}^{-1}$ de $\mathrm{P}_{2} \mathrm{O}_{5}$, $80 \mathrm{~kg} \mathrm{ha}^{-1}$ de $\mathrm{K}_{2} \mathrm{O}$ e $1,2 \mathrm{~kg} \mathrm{ha}^{-1}$ de $\mathrm{Zn}$, sem inoculação. Em virtude dos teores de cálcio e de magnésio verificados, não foi realizada calagem na área. Os demais tratos culturais e fitossanitários foram realizados quando necessários, conforme proposto por Ribeiro et al. (1999).

No material seco coletado aos 110 DAS, foi realizada a análise química de: nitrogênio total, pelo método de destilação de Kjeldahl segundo Embrapa (1997), e de P e K, a partir de digestão nítrico-perclórica (Bataglia et al., 1983). A determinação de $P$ foi feita por colorimetria (Embrapa, 1997). O Ca e Mg foram determinados por espectrofotometria de absorção atômica (Bataglia et al., 1983), o carbono orgânico (C), pelo método Walkley e Black modificado e o $\mathrm{S}$ por turbidimetria (Tedesco et al., 1985). O conteúdo total de cada nutriente foi estimado a partir da percentagem do nutriente presente em cada amostra, multiplicado pelo peso total estimado de fitomassa seca.

$\mathrm{Na}$ avaliação da taxa de decomposição e liberação de nutrientes, foram utilizadas sacolas de náilon com malha de $2 \mathrm{~mm}$ de abertura, com dimensões de 0,20x0,20 m, conforme descrito por Thomas \& Asakawa (1993) e utilizado por Torres et al. (2005), Espíndola et al. (2006) e Boer et al. (2007). A fitomassa das plantas de cobertura foi secada em estufa à temperatura de $65^{\circ} \mathrm{C}$, até peso constante, seccionada em fragmentos de $5 \mathrm{~cm}$, e foram colocados $20 \mathrm{~g}$ desse material em cada sacola. Foram distribuídas 20 sacolas na superfície do solo, em cada parcela. Foram realizadas cinco amostragens por parcela: a primeira aos 110 DAS (no manejo), a segunda aos 42 dias após dessecação com herbicida (DAM) e as demais em intervalos regulares de 56 dias, correspondendo a 0, 42, 98, 154 e 210 DAM. Em cada amostragem, coletaram-se quatro sacolas por tratamento. Após a coleta das amostras, o resíduo vegetal de cada sacola foi limpo manualmente, sobre peneira de malha de $0,053 \mathrm{~mm}$, secado em estufa de circulação forçada de ar a $65^{\circ} \mathrm{C}$ até peso constante, e depois moído.

Para descrever a decomposição dos resíduos vegetais e a liberação dos macronutrientes, aplicou-se o modelo matemático exponencial descrito por Thomas \& Asakawa (1993) e utilizado por Rezende et al. (1999), do tipo $\mathrm{X}=\mathrm{X}_{\mathrm{o}} \mathrm{e}^{-\mathrm{kt}}$, em que $\mathrm{X}$ é a quantidade de fitomassa seca remanescente após um período de tempo t, em dias; 
$\mathrm{X}_{\mathrm{o}}$ é a quantidade inicial de fitomassa seca ou de nutriente; e k é a constante de decomposição do resíduo. Com o valor de $\mathrm{k}$, calculou-se o tempo de meia-vida $\left(\mathrm{T}_{1 / 2}\right)$, que expressa o período de tempo necessário para que metade dos resíduos se decomponha ou para que metade dos nutrientes contidos nos resíduos seja liberada (Espíndola et al., 2006). Foram elaboradas equações matemáticas que representassem a decomposição de fitomassa seca e a liberação de nutrientes, com auxílio do software SigmaPlot, for Windows 4.0. Os resultados obtidos foram submetidos à análise de variância, aplicando-se o teste F para significância e as médias comparadas pelo teste de Tukey, a 5\% de probabilidade.

\section{Resultados e Discussão}

Em 2000, as gramíneas apresentaram maior produção de FS, com variação entre 2,4 e 10,3 $\mathrm{Mg} \mathrm{ha}^{-1}$. O milheto produziu a maior quantidade de FS, seguido pelo sorgo e pela braquiária, ao passo que a aveia-preta apresentou o menor valor (Tabela 1). Quanto ao milheto, Chaves (1997) obteve produção de FS idêntica, enquanto Moraes (2001), Lara Cabezas et al. (2004) e Crusciol \& Soratto (2007) observaram valores inferiores $(9,6,9,7 \mathrm{e}$ $8,9 \mathrm{Mg} \mathrm{ha}^{-1}$, respectivamente). No que se refere ao sorgo, Moraes (2001) e Oliveira (2001) observaram valores de 10,7 e 15,5 $\mathrm{Mg} \mathrm{ha}^{-1}$, respectivamente, porém, esses altos valores de FS estiveram relacionados à rebrota do sorgo. Com relação à braquiária, Nunes et al. (2006) e Crusciol \& Soratto (2007) verificaram valores de FS (6,2 $\left.\mathrm{Mg} \mathrm{ha}^{-1}\right)$ semelhantes aos observados neste estudo. Para a aveia-preta, Aita et al. (2001) e Heinrichs et al. (2001) verificaram maior produção de FS, de 4,4 e 4,9 $\mathrm{Mg} \mathrm{ha}^{-1}$, respectivamente, na Região Sul do Brasil.

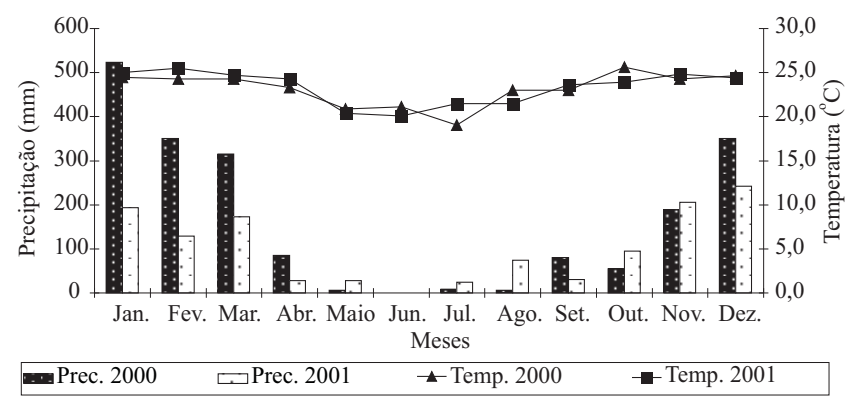

Figura 1. Temperatura e precipitação média obtidas na Estação Meteorológica da Epamig, nos anos agrícolas de 2000 e 2001, em Uberaba, MG.
A maior produtividade, observada por esses autores, pode ser explicada pelo fato de esta cultura ser adaptada a temperaturas mais baixas do que as verificadas durante o período de realização deste trabalho (Figura 1). Para o pousio (com predomínio de gramíneas), observou-se uma produção de FS de 2,1 $\mathrm{Mg} \mathrm{ha}^{-1}$.

Com relação às leguminosas, a produção de FS para guandu foi $1,6 \mathrm{Mg} \mathrm{ha}^{-1}$ e para crotalária $3,9 \mathrm{Mg} \mathrm{ha}^{-1}$ (Tabela 1). Nunes et al. (2006) obtiveram valores inferiores para crotalária $\left(2,73 \mathrm{Mg} \mathrm{ha}^{-1}\right)$ e superiores para guandu (4,0 $\left.\mathrm{Mg} \mathrm{ha}^{-1}\right)$. Salmi et al. (2006) observaram produção de FS de guandu entre 4,67 e 5,95 $\mathrm{Mg} \mathrm{ha}^{-1}$.

Na segunda etapa do estudo (2001), a semeadura das plantas de cobertura ocorreu em abril, período em que se observa diminuição da temperatura e precipitação, além disso, 2001 foi um ano atípico em relação à precipitação anual (1.249,1 mm) (Figura 1), valor inferior à média dos últimos dez anos $(1.639,6 \mathrm{~mm}$ ) (Abdala, 2005). Com relação às gramíneas, os valores de FS foram menores aos da primeira etapa, para milheto, sorgo e braquiária, e maiores para aveia-preta e pousio (Tabela 1). Nunes et al. (2006) observaram produção de 4,0 $\mathrm{Mg} \mathrm{ha}^{-1}$ em braquiária e 3,6 $\mathrm{Mg} \mathrm{ha}^{-1} \mathrm{em}$ pousio, quando semeados e cultivados em condições climáticas idênticas às deste estudo. Boer et al. (2007), no cerrado, ao cultivar milheto semeado na mesma época (abril), porém com precipitação pluvial elevada, observaram valores superiores para produção de FS $\left(10,8 \mathrm{Mg} \mathrm{ha}^{-1}\right)$. A baixa precipitação influenciou negativamente a produção de FS em 2001, ao passo que a diminuição da temperatura pode ter favorecido o aumento da produção de FS de aveia, pousio e guandu.

Tabela 1. Produção de fitomassa seca (FS) e relação C/N das plantas de cobertura, nos anos agrícolas de 2000 e 2001.

\begin{tabular}{lccccc}
\hline Planta de & \multicolumn{2}{c}{2000} & & \multicolumn{2}{c}{2001} \\
\cline { 2 - 3 } \cline { 5 - 6 } cobertura & $\mathrm{FS}\left(\mathrm{Mg} \mathrm{ha}^{-1}\right)$ & $\mathrm{C} / \mathrm{N}$ & & $\mathrm{FS}\left(\mathrm{Mg} \mathrm{ha}^{-1}\right)$ & $\mathrm{C} / \mathrm{N}$ \\
\hline Pousio & $2,1 \mathrm{~d}$ & 19,5 & & $3,8 \mathrm{a}$ & 25,3 \\
Milheto & $10,3 \mathrm{a}$ & 21,7 & & $3,6 \mathrm{a}$ & 25,3 \\
Sorgo & $7,1 \mathrm{~b}$ & 24,3 & & $4,0 \mathrm{a}$ & 34,6 \\
Crotalária & $3,9 \mathrm{c}$ & 11,5 & & $3,7 \mathrm{a}$ & 18,1 \\
Aveia & $2,4 \mathrm{~d}$ & 30,6 & & $3,4 \mathrm{a}$ & 28,3 \\
Guandu & $1,6 \mathrm{~d}$ & 11,3 & & $2,7 \mathrm{~b}$ & 16,6 \\
Braquiária & $6,0 \mathrm{~b}$ & 16,1 & & $2,1 \mathrm{c}$ & 19,6 \\
\hline CV $(\%)$ & 20,7 & - & & 10,9 & -
\end{tabular}

${ }^{(1)}$ Médias seguidas de mesma letra, na coluna, não diferem entre si a 5\% de probabilidade, pelo teste de Tukey. 
De maneira geral, a relação $\mathrm{C} / \mathrm{N}$ das gramíneas, na época de pleno florescimento está ao redor de 40:1 e, nas leguminosas, na faixa de 20:1 (Monegat, 1991). Na primeira etapa do estudo (2000), foram observados valores de relação $\mathrm{C} / \mathrm{N}$ menores que 30 e 11,5, para gramíneas e leguminosas, respectivamente (Tabela 1). No segundo período avaliado, foram verificados aumentos da relação $\mathrm{C} / \mathrm{N}$ nas coberturas avaliadas (Tabela 1).

Com relação à decomposição dos resíduos culturais, na primeira época de avaliação, a maior taxa de decomposição ocorreu até os 42 DAM. Braquiária e o pousio foram as coberturas que mais se decompuseram, enquanto o milheto apresentou a menor decomposição (Tabela 2). Moraes (2001) alcançou resultados semelhantes para decomposição aos 42 DAM para sorgo e milheto. Silva et al. (1997) observaram valores superiores para crotalária, guandu e braquiária, aos 60 DAM, nas mesmas condições climáticas.

Aos 210 DAM, observou-se a seguinte ordem decrescente de decomposição, em 2000: braquiária $(88,6 \%)>$ pousio $(87,4 \%)>$ aveia-preta $(74,2 \%)>$ sorgo $(69,4 \%)>$ guandu $(69,2 \%)>$ crotalária $(67,8 \%)>$ milheto $(67,6 \%)$ (Tabela 2). Kliemann et al. (2006) verificaram elevadas taxas de decomposição para sorgo (80 e 86\%), milheto (58 e 65\%), braquiária (56 e 62\%), guandu (65 e 79\%) aos 150 e 360 DAM (projeção estimada), respectivamente.

No ano seguinte (2001), com a diminuição da temperatura e precipitação na época de realização do experimento (Figura 1), a taxa de decomposição aos $42 \mathrm{DAM}$ foi inferior à do primeiro ano, para todas as coberturas avaliadas, com exceção do milheto. A braquiária continuou sendo a cobertura que apresentou os menores valores para FS remanescente (Tabela 2) e $\mathrm{T}_{1 / 2}$ (Tabela 3).
Aos 210 DAM verificou-se a seguinte ordem decrescente de decomposição em 2001: braquiária $(84,6 \%)>$ guandu $(77,3 \%)>\operatorname{sorgo}(70,6 \%)>$ milheto $(69,7 \%)>$ aveia-preta $(67,5 \%)>$ pousio $(65,4 \%)>$ crotalaria $(65,0 \%)$ (Tabela 2). Neste ano, resíduos culturais da crotálaria foram os que permaneceram por mais tempo sobre o solo. Silva et al. (1997) obtiveram resultados semelhantes, também no cerrado, onde as leguminosas (guandu e crotalária) se decompuseram mais lentamente, quando comparadas à braquiária.

Com relação ao cultivo de milho e soja sobre as plantas de cobertura, não houve influência destas culturas sobre a $T_{1 / 2}$, decomposição, acúmulo e liberação de nutrientes pelas plantas de cobertura.

Para acúmulo de nutrientes na FS das plantas de cobertura no primeiro ano de avaliação, observou-se que o milheto e a crotalária foram as plantas que mais acumularam N, P, Ca, Mg e S (Tabela 4). Braz et al. (2004) verificaram maior acúmulo de $\mathrm{N}$ em milheto (342 $\mathrm{kg} \mathrm{ha}^{-1}$ ), aos 52 dias após semeadura (DAS). Em guandu, Salmi et al. (2006) obtiveram elevados valores de $\mathrm{N}$ (entre 188,2 e 261,3 $\mathrm{kg} \mathrm{ha}^{-1}$ ) e P (entre 7,2 e 9,4 $\mathrm{kg} \mathrm{ha}^{-1}$ ), com uma produção de FS variando entre 4,67 e 5,95 $\mathrm{Mg} \mathrm{ha}^{-1}$.

No segundo ano de avaliação, com a diminuição de temperatura e precipitação (Figura 1), observou-se que a crotalária e o guandu foram as coberturas que mais acumularam $\mathrm{N}$, enquanto a aveia-preta e o milheto acumularam mais $\mathrm{P}, \mathrm{Ca}, \mathrm{Mg}$ e $\mathrm{S}$, quando comparados às demais gramíneas. Em relação ao ano anterior, pousio e aveia-preta acumularam mais $\mathrm{N}, \mathrm{P}, \mathrm{Ca}$ e $\mathrm{Mg}$, enquanto o guandu acumulou mais $\mathrm{N}, \mathrm{Ca}, \mathrm{Mg}$ e $\mathrm{S}$. Neste ano, a aveia-preta foi a cobertura com maior conteúdo de $\mathrm{Ca}$ (Tabela 4).

Quanto à liberação de nutrientes no primeiro ano de avaliação, observou-se que o pousio e a braquiária foram as coberturas com as maiores taxas de

Tabela 2. Percentagem de fitomassa seca remanescente aos 42, 98, 154, 210 dias após o manejo, nos anos agrícolas de 2000 e 2001.

\begin{tabular}{|c|c|c|c|c|c|c|c|c|}
\hline \multirow{2}{*}{$\begin{array}{l}\text { Planta de } \\
\text { cobertura }\end{array}$} & \multicolumn{4}{|c|}{2000} & \multicolumn{4}{|c|}{2001} \\
\hline & 42 & 98 & 154 & 210 & 42 & 98 & 154 & 210 \\
\hline Pousio & 44,6 & 32,8 & 22,6 & 12,6 & 78,0 & 64,5 & 47,3 & 34,6 \\
\hline Milheto & 64,2 & 57,6 & 43,7 & 32,4 & 63,6 & 52,6 & 39,0 & 30,3 \\
\hline Sorgo & 62,2 & 48,6 & 37,0 & 30,6 & 71,4 & 58,9 & 38,0 & 29,4 \\
\hline Crotalária & 56,2 & 45,4 & 36,3 & 32,2 & 72,5 & 62,4 & 42,8 & 35,0 \\
\hline Aveia & 56,9 & 48,7 & 35,2 & 25,8 & 80,9 & 65,9 & 40,8 & 32,5 \\
\hline Guandu & 67,5 & 51,4 & 36,8 & 30,8 & 74,5 & 51,2 & 34,8 & 22,7 \\
\hline Braquiária & 40,8 & 32,9 & 21,5 & 11,4 & 62,8 & 42,0 & 26,4 & 15,4 \\
\hline
\end{tabular}


decomposição e liberação aos 42 DAM (Tabela 2) e as menores $T_{1 / 2}$ para todos os nutrientes avaliados (Tabelas 3), com exceção do N, Ca e Mg (Tabela 3). Moraes (2001) observou maior liberação de nutrientes aos 63 DAM, entretanto o milheto apresentou $\mathrm{T}_{1 / 2}$ de 89, 43, 2756 e 69 dias para N, P, Ca, Mg e S, respectivamente, valores inferiores aos observados neste estudo. GamaRodrigues et al. (2007) observaram, em braquiária, $\mathrm{T}_{1 / 2}$ de $131,112,198$ e 122 para N, P, Ca e Mg, respectivamente, inferiores à observada neste trabalho.

Com relação à liberação de nutrientes no segundo ano de avaliação, observou-se que os valores de $T_{1 / 2}$ foram superiores na maioria dos nutrientes (Tabela 5), quando comparados ao primeiro ano. Entretanto, no milheto, sorgo e aveia-preta, a $\mathrm{T}_{1 / 2}$ do $\mathrm{N}$ diminuiu à semelhança do $\mathrm{T}_{1 / 2}$ do $\mathrm{P}$ em milheto, crotalária, aveiapreta, guandu e braquiária. Boer et al. (2007) observaram $\mathrm{T}_{1 / 2}$ superiores para o milheto, de 110, 92, 74, 107 e 74 para N, P, Ca Mg e S, respectivamente. Os maiores valores de $T_{1 / 2}$ observados neste trabalho podem ser justificados pela menor precipitação e temperatura após o manejo (dessecação) das coberturas.

Tabela 3. Tempo de meia-vida $\left(\mathrm{T}_{1 / 2}\right)$ (em dias) da fitomassa seca e dos macronutrientes remanescentes acumulados nas coberturas vegetais, no ano agrícola 2000.

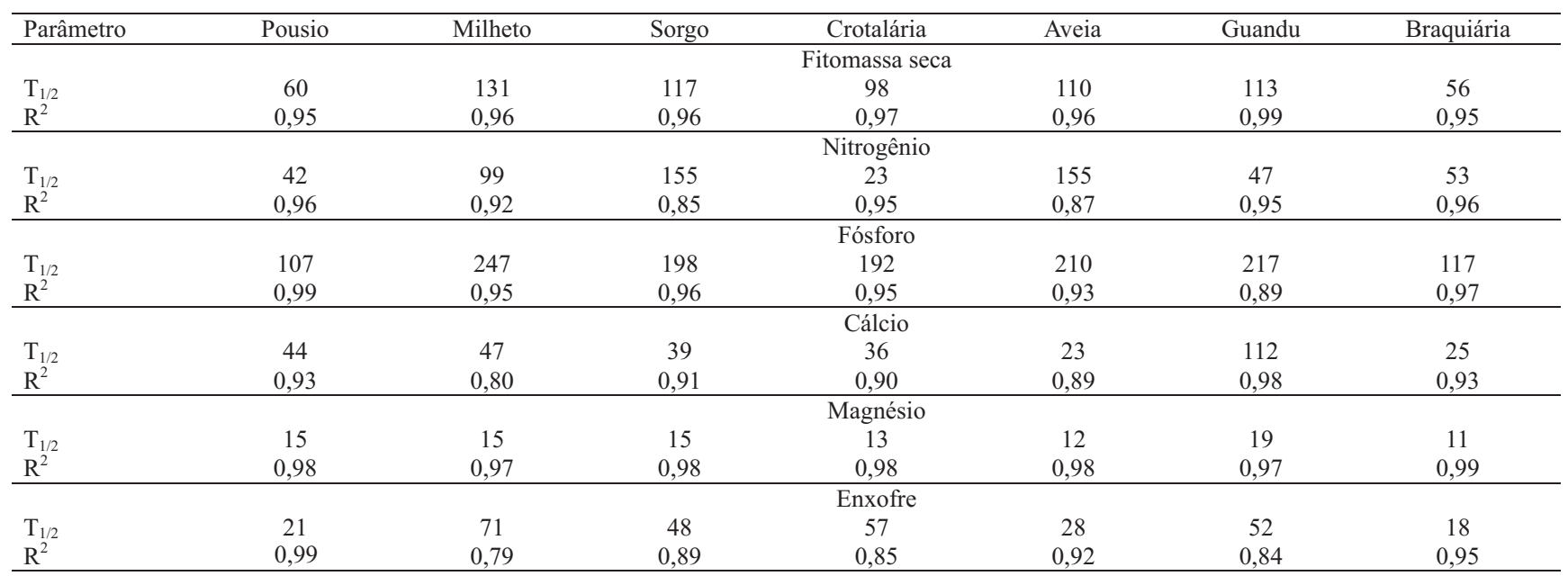

Tabela 4. Acúmulo de macronutrientes nos resíduos culturais das plantas de cobertura, nos anos agrícolas de 2000 e 2001.

\begin{tabular}{|c|c|c|c|c|c|}
\hline \multirow[t]{2}{*}{ Planta de cobertura } & $\mathrm{N}$ & $\mathrm{P}$ & $\mathrm{Ca}$ & $\mathrm{Mg}$ & $\mathrm{S}$ \\
\hline & \multicolumn{5}{|c|}{2000} \\
\hline Pousio & 46,69 & 3,55 & 19,12 & 6,30 & 11,30 \\
\hline Milheto & 165,55 & 22,60 & 41,12 & 22,60 & 13,40 \\
\hline Sorgo & 84,07 & 12,70 & 26,12 & 15,50 & 7,10 \\
\hline Cr otalária & 118,11 & 10,80 & 42,60 & 12,80 & 4,20 \\
\hline Aveia & 29,18 & 3,80 & 6,20 & 2,60 & 2,80 \\
\hline Guandu & 51,32 & 5,20 & 15,40 & 3,30 & 2,90 \\
\hline \multirow[t]{2}{*}{ Braquiária } & 130,80 & 13,30 & 18,70 & 21,10 & 9,00 \\
\hline & \multicolumn{5}{|c|}{2001} \\
\hline Pousio & 57,19 & 4,93 & 19,71 & 8,72 & 4,93 \\
\hline Milheto & 55,75 & 4,71 & 23,17 & 11,22 & 6,52 \\
\hline Sorgo & 45,00 & 5,23 & 18,49 & 8,04 & 4,42 \\
\hline Crotalária & 76,38 & 4,06 & 22,14 & 6,64 & 4,06 \\
\hline Aveia & 46,03 & 5,38 & 43,01 & 16,13 & 6,05 \\
\hline Guandu & 62,45 & 4.52 & 22,61 & 3,99 & 3,99 \\
\hline Braquiária & 41,65 & 2,33 & 8,69 & 5,94 & 3,18 \\
\hline
\end{tabular}


Tabela 5. Tempo de meia-vida $\left(\mathrm{T}_{1 / 2}\right)$ (em dias) da fitomassa seca e dos macronutrientes remanescentes acumulados nas coberturas vegetais, no ano agrícola 2001.

\begin{tabular}{|c|c|c|c|c|c|c|c|}
\hline Parâmetro & Pousio & Milheto & Sorgo & Crotalária & Aveia & Guandu & Braquiária \\
\hline & & & & Fitomassa seca & & & \\
\hline $\mathrm{T}^{1 / 2}$ & 143 & 115 & 118 & 137 & 130 & 101 & 78 \\
\hline \multirow[t]{2}{*}{$\mathrm{R}^{2}$} & 0,98 & 0,97 & 0,99 & 0,99 & 0,98 & 0,99 & 0,99 \\
\hline & & & & Nitrogênio & & & \\
\hline $\mathrm{T}^{1 / 2}$ & 95 & 88 & 98 & 66 & 123 & 66 & 78 \\
\hline \multirow[t]{2}{*}{$\mathrm{R}^{2}$} & 0,97 & 0,95 & 0,96 & 0,96 & 0,98 & 0,99 & 0,98 \\
\hline & & & & Fósforo & & & \\
\hline $\mathrm{T}^{1 / 2}$ & 289 & 210 & 192 & 267 & 267 & 173 & 151 \\
\hline \multirow[t]{2}{*}{$\mathrm{R}^{2}$} & 0,79 & 0,90 & 0,94 & 0,86 & 0,77 & 0,91 & 0,96 \\
\hline & & & & Cálcio & & & \\
\hline$T^{1 / 2}$ & 38 & 47 & 30 & 38 & 33 & 79 & 37 \\
\hline \multirow[t]{2}{*}{$\mathrm{R}^{2}$} & 0,96 & 0,94 & 0,95 & 0,93 & 0,96 & 0,91 & 0,94 \\
\hline & & & & Magnésio & & & \\
\hline $\mathrm{T}^{1 / 2}$ & 18 & 19 & 16 & 43 & 17 & 18 & 19 \\
\hline \multirow[t]{2}{*}{$\mathrm{R}^{2}$} & 0,97 & 0,97 & 0,97 & 0,97 & 0,96 & 0,97 & 0,97 \\
\hline & & & & Enxofre & & & \\
\hline $\mathrm{T}^{1} / 2$ & 84 & 61 & 54 & 69 & 99 & 42 & 34 \\
\hline $\mathrm{R}^{2}$ & 0,60 & 0,60 & 0,71 & 0,67 & 0,67 & 0,84 & 0,84 \\
\hline
\end{tabular}

\section{Conclusões}

1. O milheto e a crotalária são as plantas de cobertura com maior produção de fitomassa seca e acúmulo de nitrogênio nos dois períodos avaliados, entre as gramíneas e leguminosas, respectivamente.

2. A maior taxa de decomposição das plantas de cobertura e de liberação de nutrientes ocorre aos 42 dias após a dessecação.

3. A braquiária apresenta a maior taxa de decomposição.

4. Os maiores tempos de meia-vida ocorrem para fósforo e os menores para magnésio.

\section{Referências}

ABDALA, V.L. Zoneamento ambiental da bacia do alto curso do rio Uberaba-MG como subsídio para gestão do recurso hídrico superficial. 2005. 73p. Dissertação (Mestrado) - Universidade Federal de Uberlândia, Uberlândia.

AITA, C.; BASSO, C.J.; CERETTA, C.A.; GONÇALVES, C.N.; ROS, C.O. Plantas de cobertura do solo como fonte de nitrogênio ao milho. Revista Brasileira de Ciência do Solo, v.25, p.157-165, 2001.

AITA, C.; GIACOMINI, S.J. Decomposição e liberação de nitrogênio dos resíduos culturais de plantas de cobertura de solo solteiras e consorciadas. Revista Brasileira de Ciência do Solo, v.27, p.601612, 2003.

BATAGLIA, O.C.; FURLANI, A.M.C.; TEIXEIRA, J.P.F.; GALLO, J.R. Métodos de análises química de plantas. Campinas: Instituto Agronômico de Campinas, 1983. 48p. (IAC, Boletim técnico, 78).
BERTOL, I.; CIPRANDI, O.; KURTZ, C.; BAPTISTA, A.S. Persistência dos resíduos culturais de aveia e milho sobre a superfície do solo em semeadura direta. Revista Brasileira de Ciência do Solo, v.22, p.705-712, 1998.

BOER, C.A.; ASSIS, R.L.; SILVA, G.P.; BRAZ, A.J.B.P.; BARROSO, A.L.L.; CARGNELUTTI FILHO, A.; PIRES, F.R. Ciclagem de nutrientes por plantas de cobertura na entressafra em um solo de cerrado. Pesquisa Agropecuária Brasileira, v.42, p.1269-1276, 2007.

BRAZ, A.J.B.P.; SILVEIRA, P.M. da; KLIEMANN, H.J.; ZIMMERMANN, F.J.P. Acumulação de nutrientes em folhas de milheto e dos capins braquiária e mombaça. Pesquisa Agropecuária Tropical, v.34, p.83-87, 2004.

CAIRES, E.F.; GARBUIO, F.J.; ALLEONI, L.R.F.; CAMBRI, M.A. Calagem superficial e cobertura de aveia preta antecedendo os cultivos de milho e soja em sistema de plantio direto. Revista Brasileira de Ciência do Solo, v.30, p.87-98, 2006.

CHAVES, C.A.S. Produção e valor nutritivo das silagens de capim Sudão (Shorgum sudanense (Piper) Stapf), milheto (Pennisetum americanum (L.) Leeke), teosinto (Euchlaena mexicana Scharad) e milho (Zea mays L.). 1997. 56p. Dissertação (Mestrado) Universidade Federal de Lavras, Lavras.

CRUSCIOL, C.A.C.; SORATTO, R.P. Nutrição e produtividade do amendoim em sucessão ao cultivo de plantas de cobertura no sistema plantio direto. Pesquisa Agropecuária Brasileira, v.42, p.15531560, 2007.

EMBRAPA. Manual de métodos de análise de solos. 2.ed. Rio de Janeiro: Embrapa-CNPS, 1997. 212p.

EMBRAPA. Sistema brasileiro de classificação de solos. Brasília: Embrapa-SPI; Rio de Janeiro: Embrapa-CNPS, 1999. 412p.

ESPINDOLA, J.A.A.; GUERRA, J.G.M.; ALMEIDA, D.L. de; TEIXEIRA, M.G.; URQUIAGA., S. Decomposição e liberação de 
nutrientes acumulados em leguminosas herbáceas perenes consorciadas com bananeira. Revista Brasileira de Ciência do Solo, v.30, p.321-328, 2006.

FEDERAÇÃO BRASILEIRA DE PLANTIO DIRETO NA PALHA. Evolução do plantio direto no Brasil. Disponível em: http://www.febrapdp.org.br/port/plantiodireto.html. Acesso em: 21 fev. 2008.

GAMA-RODRIGUES, A.C.; GAMA-RODRIGUES, E.F.; BRITO, E.C. Decomposição e liberação de nutrientes de resíduos culturais de plantas de cobertura em Argissolo Vermelho-Amarelo na região noroeste fluminense-RJ. Revista Brasileira de Ciência do Solo, v.31, p.1421-1428, 2007.

HEINRICHS, R.; VITTI, G.C.; MOREIRA, A.; FANCELLI, A.L. Cultivo consorciado de aveia e ervilhaca: relação $\mathrm{C} / \mathrm{N}$ da fitomassa e produtividade do milho em sucessão. Revista Brasileira de Ciência do Solo, v.25, p.331-340, 2001.

KLIEMANN, H.J.; BRAZ, A.J.P.B.; SILVEIRA, P.M. Taxa de decomposição de resíduos de espécies de cobertura em Latossolo Vermelho Distroférrico. Pesquisa Agropecuária Tropical, v.36, p.21-28, 2006.

LARA CABEZAS, W.R.L.; ALVES, B.J.R.; URQUIAGA, S.; SANTANA, D.G. Influência da cultura antecessora e da adubação nitrogenada na produtividade de milho em sistema plantio direto e solo preparado. Ciência Rural, v.34, p.1005-1013, 2004.

MONEGAT, C. Plantas de cobertura do solo: características e manejo em pequenas propriedades. Chapecó: Ed. do Autor, 1991. $336 \mathrm{p}$.

MORAES, R.N.S. Decomposição das palhadas de sorgo e milheto, mineralização de nutrientes e seus efeitos no solo e na cultura do milho em plantio direto. 2001. 90p. Dissertação (Mestrado) - Universidade Federal de Lavras, Lavras.

NUNES, U.R.; ANDRADE JÚNIOR, V.C.A.; SILVA, E.B.; SANTOS, N.F.; COSTA, H.A.O.; FEREIRA, C.A. Produção de palhada de plantas de cobertura e rendimento do feijão em plantio direto. Pesquisa Agropecuária Brasileira, v.41, p.943-948, 2006.
OLIVEIRA, T.K. Plantas de cobertura em cultivo solteiro e consorciado e seus efeitos no feijoeiro e no solo em plantio direto. 2001. 109p. Dissertação (Mestrado) - Universidade Federal de Lavras, Lavras.

REZENDE, C.P.; CANTARUTTI, R.B.; BRAGA, J.M.; GOMIDE, J.A.; PEREIRA, J.M.; FERREIRA, E.; TARRE, R.; MACEDO, R.; ALVES, B.J.R.; URQUIAGA, S.; CADISCH, G.; GILLER, K.E.; BODDEY, R.M. Litter deposition and disappearance in Brachiaria pastures in the Atlantic forest region of the South of Bahia, Brazil. Nutrient Cycling in Agroecosystems, v.54, p.99-112, 1999.

RIBEIRO, A.C.; GUIMARÃES, P.T.G.; ALVAREZ VENEGAS, V.H. Recomendações para o uso de corretivos e fertilizantes em Minas Gerais: 5a aproximação. Viçosa: CFSEMG, 1999. 359p.

SALMI, G.P.; SALMI, A.P.; ABBOUD, A.C.S. Dinâmica de decomposição e liberação de nutrientes de genótipos de guandu sob cultivo em aléias. Pesquisa Agropecuária Brasileira, v.41, p.673$678,2006$.

SILVA, M.L.N.; CURI, N.; BLANCANEAUX, P.; LIMA, J.M.; CARVALHO, A.M. Rotação adubo verde:milho e adsorção de fósforo em Latossolo Vermelho-Escuro. Pesquisa Agropecuária Brasileira, v.32, p.649-654, 1997.

TEDESCO, M.J.; VOLKWEISS, S.J.; BOHNEN, H. Análise de solo, plantas e outros materiais. Porto Alegre: UFRGS, 1985. 188p. (Boletim técnico de solos, n.5).

THOMAS, R.J.; ASAKAWA, N.M. Decomposition of leaf litter from tropical forage grasses and legumes. Soil Biology \& Biochemistry, v.25, p.1351-1361, 1993.

TORRES, J.L.R. Estudo das plantas de cobertura na rotação milho-soja em sistema de plantio direto no cerrado, na região de Uberaba-MG. 2003. 125p. Tese (Doutorado) - Universidade Estadual Paulista, Jaboticabal.

TORRES, J.L.R.; PEREIRA, M.G.; ANDRIOLI, I.; POLIDORO, J.C.; FABIAN, A.J. Decomposição e liberação de nitrogênio de resíduos culturais de plantas de cobertura em um solo de cerrado. Revista Brasileira de Ciência do Solo, v.29, p.609-618, 2005.

Recebido em 5 de novembro de 2007 e aprovado em 20 de fevereiro de 2008 